\title{
A GEODATABASE FOR MULTISOURCE DATA MANAGEMENT APPLIED TO CULTURAL HERITAGE: THE CASE STUDY OF VILLA BUONACCORSI'S HISTORICAL GARDEN
}

\author{
E. S. Malinverni ${ }^{1} *$, S. Chiappini ${ }^{1}$, R. Pierdicca ${ }^{1}$ \\ ${ }^{1}$ Università Politecnica delle Marche, Dipartimento di Ingegneria Civile, Edile e dell’Architettura, 60100 Ancona, Italy \\ (e.s. malinverni, r.pierdicca, s.chiappini)@staff.univpm.it;
}

KEY WORDS: UAV, Geodatabase, Cultural Heritage, Historical Garden, GIS, 3D Mapping, Data Management.

\begin{abstract}
:
In recent years, the digitization of historical data related to the architectural heritage and the development of ICT-based methodologies applied to cultural goods have become increasingly relevant. In this context, the use of GIS (Geographical Information System) is growing significantly, with the aim of collecting, analysing and managing heterogeneous data in a spatial context. Given such premise, the site identified for this case-study is a historical Italian Garden into the Villa Buonaccorsi in Potenza Picena (MC, Italy). The project aims at creating a methodology, that organizing natural and artificial elements in the GIS, to support management and planning of this landscape architecture, considering also the changes during the time. A suitable GIS can promote and ensure a correct use of the heritage knowledge, preserving the historical identity, overlaying the data. The data management system, specifically developed for this case, is based on an open source GIS, where surveyed data coming from different sources and the relation to the attributes have been descripted in a conceptual model. The inventory of this geodatabase, in a dedicated GIS, has allowed to perform some queries, making in output a dialogue box with all the information, in form of report, useful to the manager of a historical garden. The structure of the GIS can significantly to help who works with similar cases and it can be useful for analysis, management, storage and integration of information related to Italian gardens.
\end{abstract}

\section{INTRODUCTION}

There are many sites of historical and cultural interest that, given their value, are increasing their interest and are thus under public safeguard. This process led to numerous, complex and important studies that have been carried out over the years. However, thanks to the advent of new technologies, developed exponentially in recent years, these studies have become faster, more accurate, easily integrated and affordable. Regardless the typology of good to be preserved (archaeological sites, simple statues, gardens or villas) the process of collecting meaningful information and data is valid for any cultural field; what makes these data reliable, affordable and long-lasting, is the process of organizing, in a simple and reliable way. This is precisely one of the motivations that should to make us understand the need to develop and promote the digital and innovative technologies. The potential offered in the field of Geomatics by technologies like Unmanned Aerial Vehicles (UAV) or Geographic Information System (GIS), in the design and information management for the cultural heritage care, is huge and moreover the digital data acquisition is considered an important task for the valorisation of cultural assets. Nowadays, other benefits are provided by the ICT multimedia tools. The knowledge and enjoyment of a place does not necessarily require a physical visit, but, with new social platforms and virtual systems that can be easily shared online enhanced and updated thanks to numerous customers and users of the web application. The work described in this paper is aimed at actively contributing to the management of a green area in form of a garden, giving an input to the protection of the architectural landscape, made of building heritage, floral architectural and sculptures: the historical Italian garden of the Villa Buonaccorsi at Potenza
Picena (MC, Italy). This big built and natural complex, which is subject to the requirements of ordinary maintenance and to the risks of deterioration is studied to preserve the green area linked to the historical buildings. In a specific case, the concept of preservation of historical gardens in Italy. is, formalized with the Florence Charter, 1981 (ICOMOS, 1982). The concept is relatively recent with respect to the established principles of restoration of architectural, painting and sculptural heritage, a topic already known in international debate, but which had not yet reached a mature awareness. The research project, as told above, aims to use methods and techniques of Geomatics to provide digital products for knowledge, analysis and communication/spreading to give the enhancement of cultural heritage, architecture and landscape. The use of management tools like GIS goes in parallels with the recent improvement of data collection techniques, like for instance drones, allowing to perform scheduled aerial shots, with significant benefits such as high speed of data acquisition for the surveying with detail and lower logistical commitment of execution. Photogrammetry (also low cost one for close range purposes) is well known and it can provide 3D models of real objects. Nowadays, the integration of sensors and new digital automatic solutions have given a new improvement to this technique, overcoming the laser scanner tools. So, the use of the UAV to give photogrammetric products, integrates the surveying techniques, not replacing the classical methods, but rather making it complementary to them. The image processing of UAV acquisition generates point clouds, producing DTM, DSM and consequently orthoimages, to complete the knowledge of the real object. Close range photogrammetry integrates the detail of the scene. This data collection can provide a geometric base for the measurements and the object properties can be augmented,

\footnotetext{
* Corresponding author
} 
linking dedicated attributes. At this point, in the last decades all the information can be organized in a GIS and to perform this task it is possible to use an opensource QGIS (QGIS Development Team, 2016). The reason of this boost in its use lies on its excellent usability and versatility; in fact, there are several cases in which GIS has been chosen, especially for the management of green areas in several cities. An example is an application to the city of Milan, where it has allowed to improve the management of a public asset, combining GIS features, attributes and data coming from different services, to use in a unique geodatabase. GIS offers great benefits to organize e manage buildings of historical and cultural interest, for their conservation and maintenance. The information, in form of qualitative and quantitative data, sometimes resulting from monitoring, can be managed in GIS to considering the change detection of the site or its management service. In this case one of the main advantages is the ability to define any necessary operation with the quantification of costs as well as in the programming of subsequent controls at different times and scales, depending on the seriousness of the phenomena. Different applications refer the possibility to combine the management of historical buildings with their related gardens. This paper illustrates a methodology to support documentation and management, considering the time, of a beautiful historical architecture with its gardens. By means of the data collection and its organization in a relational geo-documentation system we provide a GIS to manage data at different levels, with the possibility to build from queries new information (interpretative and predictive plans) suitable for a decision support system.

\section{THE CASE OF STUDY: VILLA BUONACCORSI}

The Villa Buonaccorsi with its Gardens (Panzini, 1998) is located in Potenza Picena (MC), a small town in the center of Italy (figure 1). It was maybe developed around sixteenthcentury and is extended for 5 hectares. It was the summer residence of the Buonaccorsi family.

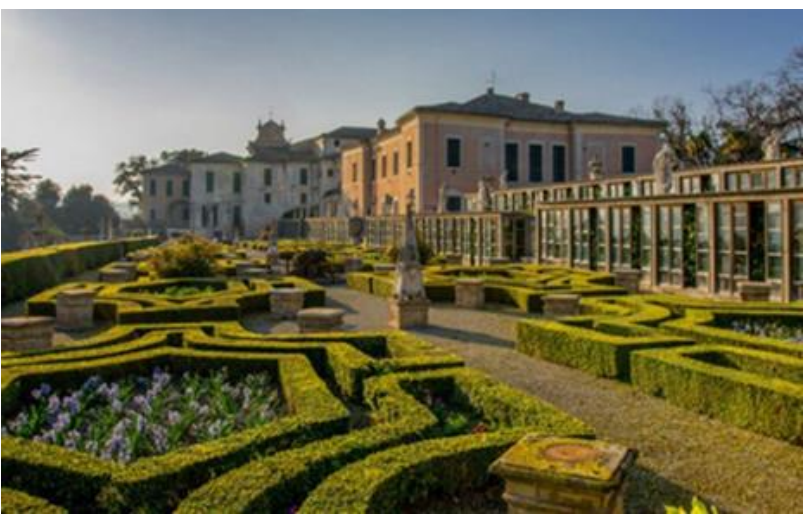

Figure 1. Villa Buonaccorsi and its typical Italian Garden

The central body of the building was composed of a semi basement floor dedicated to kitchens and other service rooms; a ground floor was dedicated mainly to the dining room and at the first floor there were the collection of books. The north wing, separated from the Villa, housed the administrative offices and the semi basement floor, was employed as storehouse. The true jewel of the Villa is its Italian Garden that created a wonderful relationship between art and nature. It is exposed completely to the South and protected by dense grove; the environment is suitable for the flowering of citruses, grown in espalier and placed in larges ground nineteenth-century pots.
It is developed in five terraces crossed and joined by a large central staircase; there are two intermediate levels and it is surrounded by walls, outside of which, there is a natural wood on some sides of the hill. Following the description of the terraces, showed in figure 2 .

1) The first terrace, the highest and smallest, has the appearance of a "secret garden". Composed of four parts defined by paths of white gravel with at the centre a fountain; the paths are bordered by hedgerows including seasonal flowers, along many statues are located and terracotta pots contain citrus trees.

2) The second terrace, about double of the first, has eight flowerbeds, decorated with a regular sequence of citrus in terracotta pots, fountains and obelisks.

3) By a central staircase with the statues of Arlecchino and Pulcinella, you reach the third level where the style of the Renaissance is mainly represented, in fact the avenue is flanked by statues of Roman emperors, hedgerows, roses and oleanders. The floor is closed at the end by a niche with the statue of the goddess Flora;

4) This fourth level is composed by rectangular flowerbeds, without statues or decorations;

5) The fifth terrace shades the countryside without avoid the view of the hills. It is composed of four parallel rows of laurel trees and two large fishponds with water lilies.

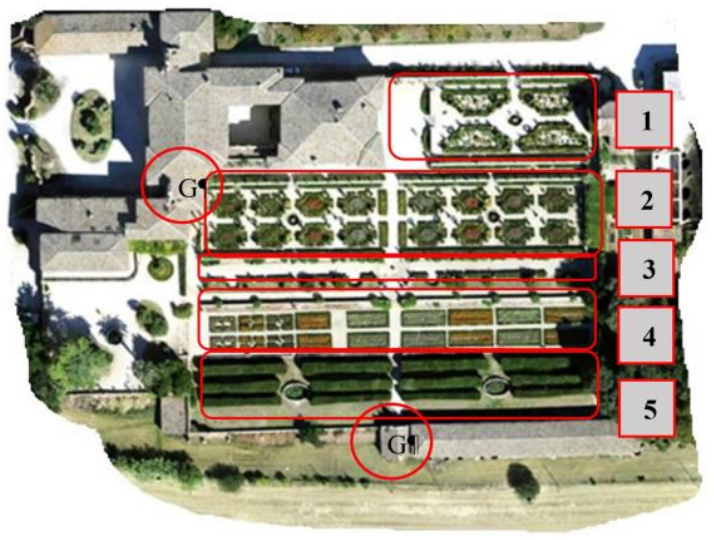

Figure 2. The subdivision of the Italian Garden in terraces

In the Villa there are two distinct caves (indicated by the letters $\mathrm{G}$ in the figure 2) with the best-preserved examples of automatons in Italy. The first, located in a building in the fifth terrace, is called "Grotta degli automi" with the polychrome figure of "Cecco Birbo" and the other ones in three niches (Figure 3).

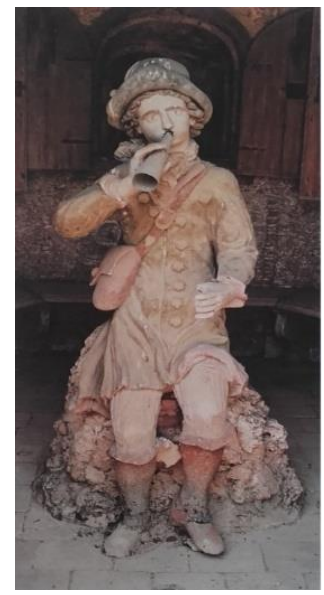

Figure 3. The polychrome figure of "Cecco Birbo" in the " "Grotta degli automi" 
The other cave, called "Grotta dei Frati", is composed of statues of two monks, leaning against the walls, which flank a niche closed by a wooden door. At its opening appears a devil splashing water.

In the garden are visible also beautiful statues, in total 149 , whose 105 only in the Garden, dating at the first half of the eighteenth century, by Orazio Marinali, which name is written on the statue basement. On the East side of the Garden there is the building of the Villa, while to the other side there is a small eighteen century baroque church, dedicated to San Filippo Neri. Furthermore, towards the East side, there is the English Garden, made at the end of eighteen century, but today completely abandoned and without its original structure.

\section{STATE OF THE ART}

The literature review brings several projects made with the aim to create a customized geographic information system to manage green area and in particular gardens (public and private). They present an improvement in relation to the cultural landscape management using the 3D mapping, applied to analysis, documentation, conservation and recovering of cultural site, and its use in a GIS, improves the usability and versatility of a geodatabase. The project for the management of green public space in the city of Milan (Guzzetti et al. 2010) interests the restoration and requalification activities. To ensure a standard of quality in the site maintenance, the municipality made a set of rules, and gave to an external service the data collection and processing of the municipal green areas. By GIS it has been possible to maximize the management of the information, storing the attributes in a unique database, archiving also the data related to planned actions.

Another example is referred to the church Parrocchiale of Vilminore di Scale (BG, Italy) (Coccoli et al., 2003). The use of GIS validates the possibility to create and manage the available information, making them always quickly accessible. The purpose is a planning of conservation to manage the data of the project, cataloguing the documentation of the restoration, until the scheduled maintenance phase. The organization of a geodatabase for the conservation management, furthermore, enables the prediction of the dynamic degradation factors and the building information system.

An archiving system and documentation, based on web, is related to an application in Castelfranco Veneto (TV, Italy) (Guarnieri et al., 2016). In this case the purpose is to manage multi-source and multi-time data related to a cultural heritage site. The geodatabase is made up of historical information, documents, descriptions of artistic features of building and its park, with text and pictures. It was developed by PostgreSQL and PostGIS in the spatial environment and exported on WebGIS platform.

There is also a study to explore the use of existing waterways (Boriani et al., 2005). The authors examine the Project "Voies d'Eau Vivantes", EU Terra Programme, and the GIS potentialities, with the goal to survey historical sites by features, adding cultural and natural attributes, thematic landscape analysis and urban conservation problems, in order to reach a proper approach to preserve and manage historical heritage. The final objective was the preservation and the rehabilitation of urban and suburb areas, close to Milan.

The project DILAS (Digital Landscape Server) (Wüst et al., 2004) had the purpose to generate, manage and visualize in efficient way a large 3D landscape and some city models. The paper highlights some of specific requirements that include object geometries and photo-realistic textures and illustrates how these have been organized in DILAS, to integrate space and time. DILAS is based on an object-oriented topological 3D data model. This model is automatically mapped in Java and in XML representation, which is stored in an object-relational DBMS (Oracle 9i). The case study choses the castle of Wildenstein, BL (Switzerland).

\section{THE GEODATABASE}

This paragraph describes all data that have been collected and processed to organize the geodatabase managed in the GIS about the Buonaccorsi's Italian Garden. The data acquisition in cartographic form (vector and raster) are the basic information allowing in the next step to monitor the natural and artificial characteristics of the site.

\subsection{UAV photogrammetric data acquisition}

The mapping of the whole site was obtained by a photogrammetric survey with a 3D Iris UAV (Unmanned Aerial Vehicle) (D. Mustaka, 2016). The surveying has involved at first the measurements of 18 retroreflective targets by the GPS to georeferenced the 577 images acquired by the Canon PowerHots S100 camera, at the flight height of $45 \mathrm{~m}$, giving a GSD of $1.57 \mathrm{~cm}$. The digital photogrammetric restitution was performed by Photoscan software (Furukawa, 2015), with an RMSE report showed in the Table 1, to obtain a cloud of points and to reconstruct the geometry of the landscape (3D mesh) to product a correct orthoimage (figure 4), on the reference frame WGS84/UTM zone $33 \mathrm{~N}$, applied as a texture on the mesh (figure 5).

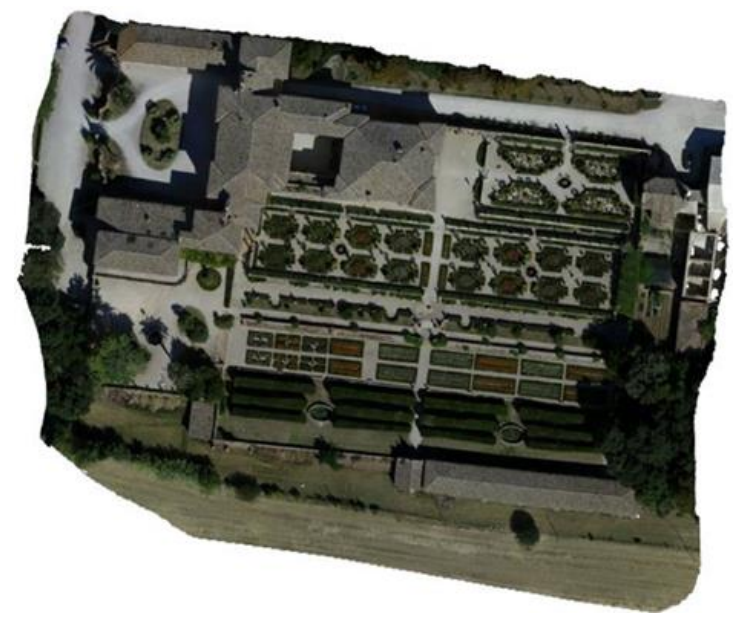

Figure 4. Orthoimage

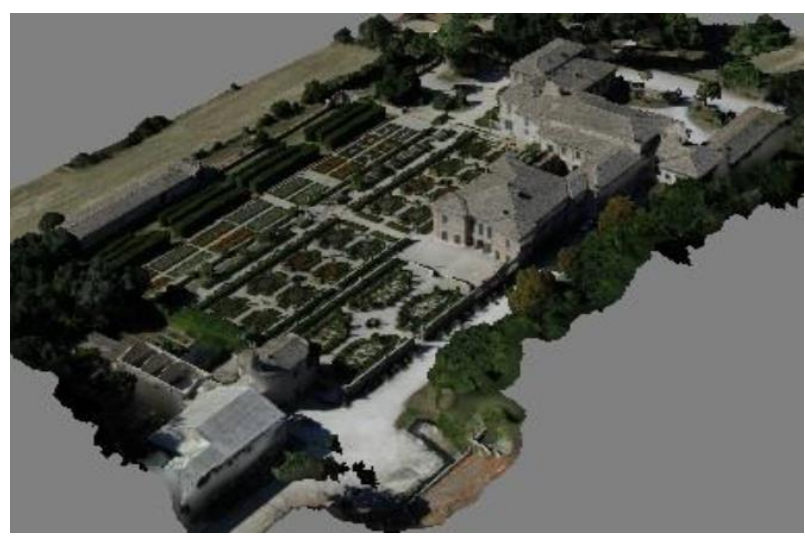

Figure 5. 3D textured mesh 


\begin{tabular}{|c|c|c|c|c|c|}
\hline Targets & $\begin{array}{c}\mathbf{X} \text { error } \\
(\mathbf{c m})\end{array}$ & $\begin{array}{c}\text { Y error } \\
(\mathbf{c m})\end{array}$ & $\begin{array}{c}\mathbf{Z} \text { error } \\
(\mathbf{c m})\end{array}$ & $\begin{array}{c}\mathbf{X Y} \text { error } \\
(\mathbf{c m})\end{array}$ & $\begin{array}{c}\text { Total } \\
(\mathbf{c m})\end{array}$ \\
\hline 18 & 1,61 & 2,52 & 5,00 & 2,99 & 5,82187 \\
\hline
\end{tabular}

Table 1. Ground control points RMSE

\subsection{The survey and the cataloguing of the statues}

The study of the statuary apparatus of the Buonaccorsi's Garden was carried out with a close-range photogrammetric survey for the 81 statues, using a Canon DSC-HX50 camera, with dpi 20.4 mega pixels and the $30 \mathrm{~mm}$ lens (Mandolesi, 2017). For each statue were taken more of 100 images at the distance of $1.5 \mathrm{~m}$ from the object. At now only10 statues have been completely surveyed, allowing the creation of the $3 \mathrm{D}$ models by Photoscan software using the same procedure of SfM (figure 6).

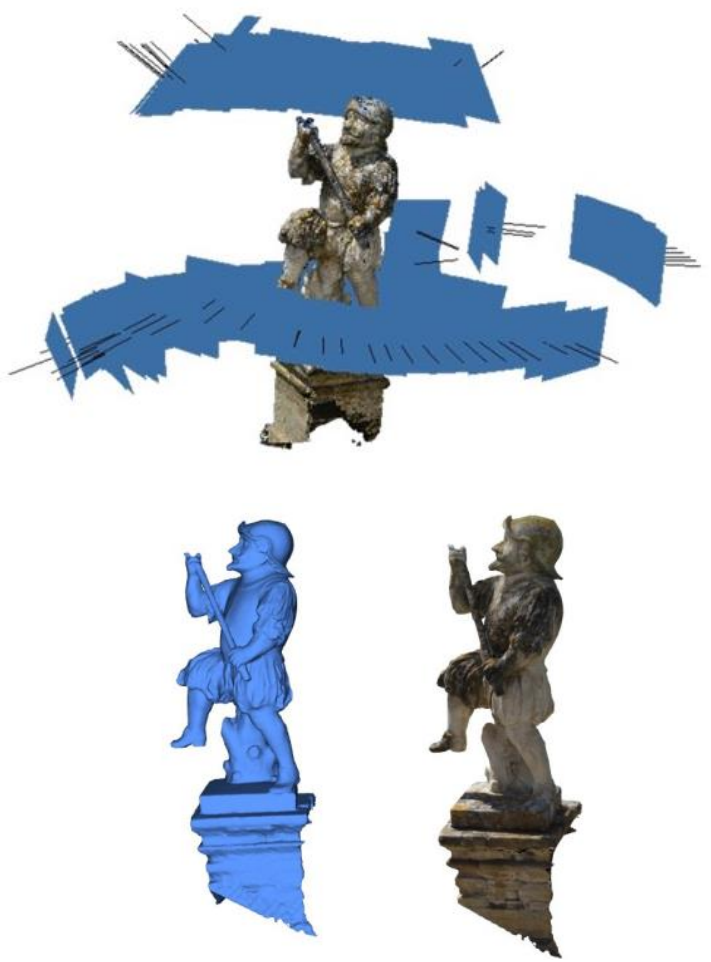

Figure 6. The survey of a statue: data acquisition on the top, 3D mesh (sx) and textured model (dx)

For any statue was made a report containing an image, an identification code, the name of the subject (if it is known), a list of materials of which it is made, a description of the state of conservation, an image related to the location on the orthoimage map and finally the 3D model.

\subsection{Geodatabase conceptual model}

The data related to the Buonaccorsi's Italian Garden are organized in a geodatabase, dedicated and designed following the conceptual model showed in figure 7. The database is structured like a Relational Data Base Management System (RDBMS), allowing the data management on the relationship model proposed by Codd (Codd, 1970).

Planning a database, it must be formalised in a conceptual model, enables to describe the data organization in a level of abstraction. The conceptual model is the formal representation of ideas and knowledge related at an event. The model may take several forms. The more used diagram is entity-relations, where the attributes are the core of the system.

The conceptual model of the geodatabase of the Italian Garden subdivides the objects of interest in Natural and Artificial elements. Each part organizes, at different levels of detail, the related tables, to manage the single components with own attributes and specific characteristics.

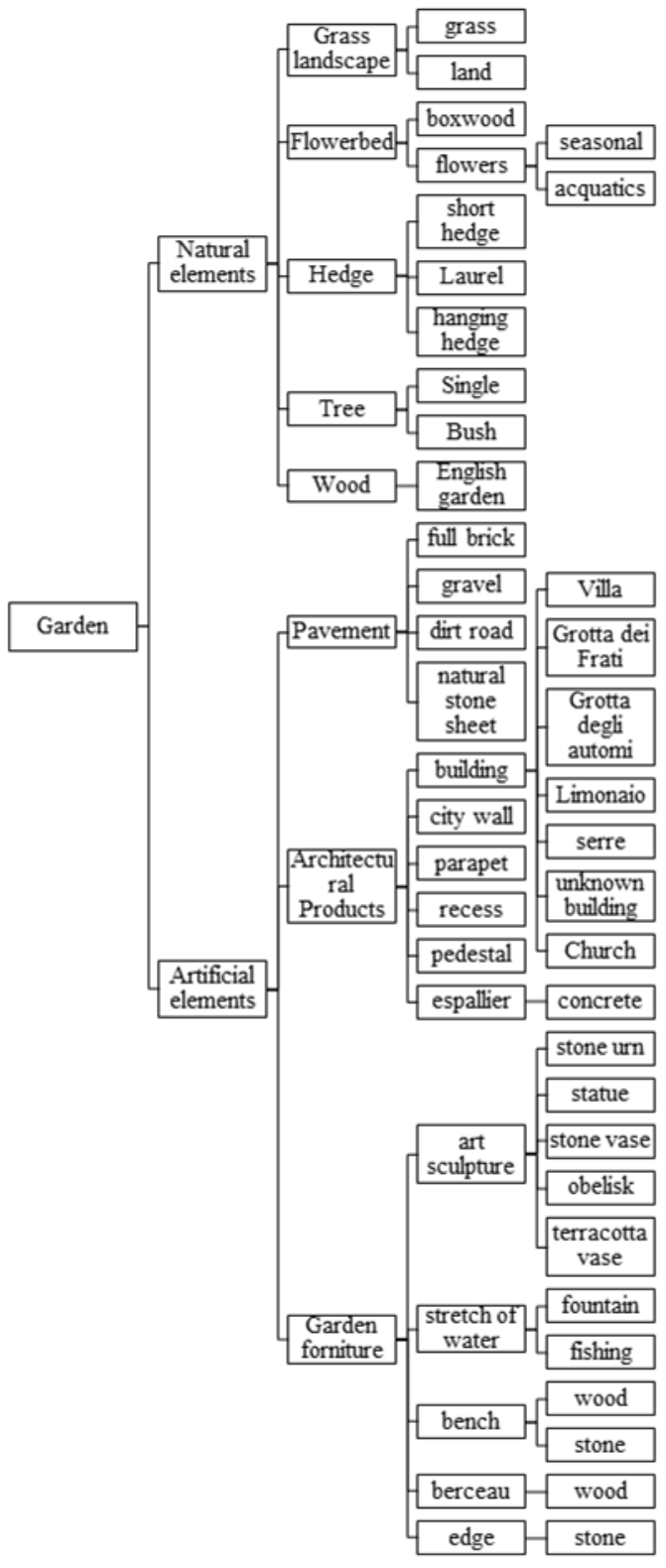

Figure 7. Conceptual model with the relationships about Natural and Artificial data of the Garden

According to a logical structure, the tables will be linked to the georeferenced vector data (points, polylines and polygons) which represent the single objects in the Garden, identifying the correct relationship by means a univocal identification (ID) code.

The main elements with which it is possible to create an entityrelations model are the attributes that describe the elementary properties of entities or relations considered relevant for the description of the reality considered. Other consistencies of the entity-relations model is the cardinality between relations and 
attributes. One can distinguish three types of relations: one to one; one to many; many to many. An example of relation is based on the Pedestal object, referred both to the "sculpture" and "terracotta pot" then linked to the "lemon tree" (figure 8). This has a relation one to one, to allow the coupling of data.

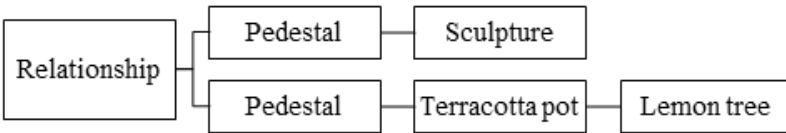

Figure 8. Example of relation that involves the Pedestal

The geodatabase represents a fundamental resource for different end users, because it can facilitate the management of the resources. Take into account the seasons (spring and autumn), the attribute that identifies the type for the natural elements (flowers) changes in the time. This variability is stored in the geodatabase and in very fast and simple way can be retrieved by a query coming useful for the periodical monitoring of colour and shape variations of the flowers in the Garden.

\section{GIS IMPLEMENTATION}

The Natural and Artificial elements inside the Italian Garden are represented by features in the open source QGIS. The mapping in QGIS is managed by shapefiles and it is derived by the drawing on the orthoimage (figure 9), suitable to manage each record referred to the identified entities. Topological rules and some geometrical constraints allow to fit the characteristics of the features in the shapefile with the survey data. For example: all the entities in the shapefile have to ensure a full coverage of the analysed site, without gap of information; all the entities in the shapefile have not to overlap each everyone and many other rules that must respect the overlapping or the topological aspects.

Finally, the mapping of English Garden is added, to complete the area of the Villa, also if it has not been surveyed by UAV, but by the digitalization of a map, drawn up in the book "I Giardini delle Marche" (Panzini, 1998).

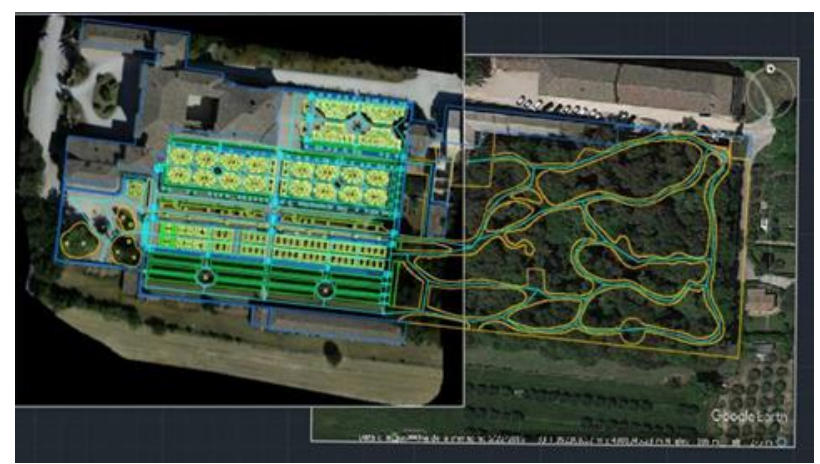

Figure 9. The mapping of the Gardens collected into the geodatabase

At this point, after creating the various layers in vector format in QGIS, the assignment of the attribute (stored in simple tables) can be performed in two manners. One can be performed selecting the layer of an object, opening the attribute table and adding the necessary fields, assigning manually to the features the inherent attributes. This is time consuming but ensures the uniqueness and integrity of the data and reduces the mistakes. The second one, faster, is based on using the join command in
QGIS, to associate attributes into the table to different objects/features. The result of a join is therefore a table (destination) that receives the information derived from another table (source). We adopted the second one, filling the geodatabase with any information.

The database organization (tables and features) facilitates the following data entry and especially simplifies the extraction of thematic data by means of queries or filters. By the SQL (Structured Query Language), it is possible to extract from the entire dataset a small set of elements, useful to perform selected analysis and thematic classification (figure 10). This means that the integrity of the data is important, as it is important the maintenance of its correctness and consistency to avoid possible errors. This makes an easy management, an excellent accessibility, reliability and independence of the data. In particular, the data structure of the geodatabase, which collects Artificial and Natural elements include also images, card and 3D representation, easy to consult in detail (figure 11), choosing some actions in QGIS, or summarize this information in a single report. The queries that can be solved in this work are many and different, depending on the request of the end user. In fact, the user can utilize the reports, as an easy way to manage the results in relation to the needs (figure 12).

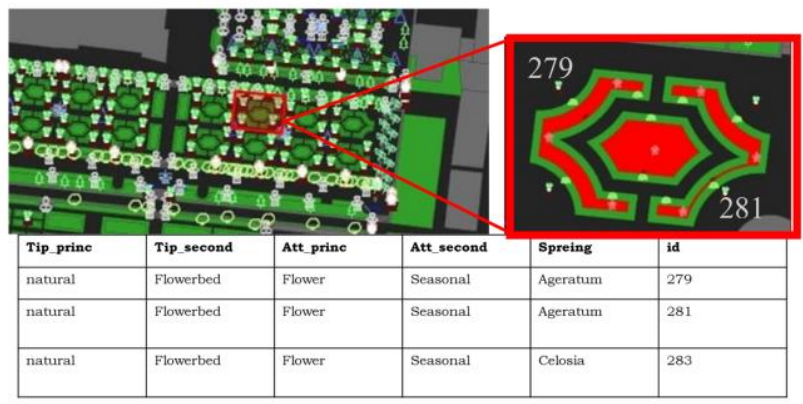

Figure 10. Query selection useful to the gardener to know the type of flowers inside the flowerbed

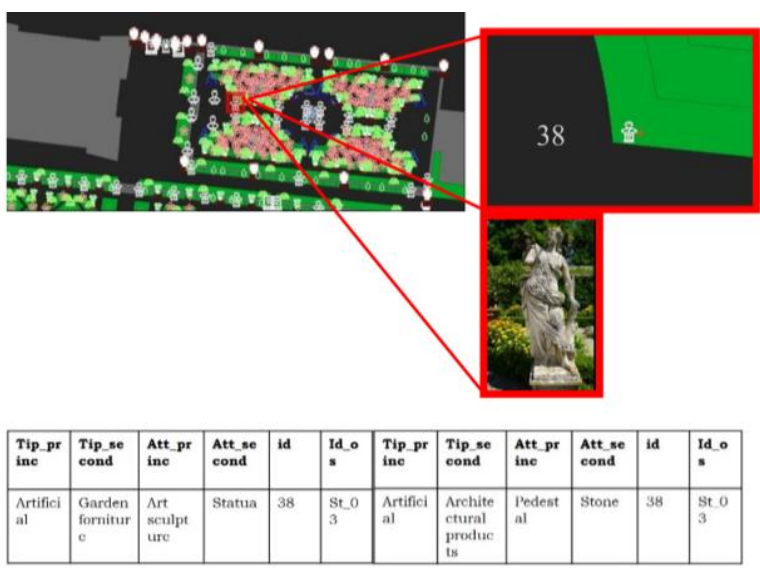

Figure 11. Query selection related to a statue with some multimedia information

Finally, the representation of the Garden has been improved, defining some class of symbology, with the aim of creating different thematic maps (figure 13). The choice of the symbology to associate to the legend classes is important to improve the reading of the investigated site and ensure a correct representation of the analysis performed in relation to different theme. 


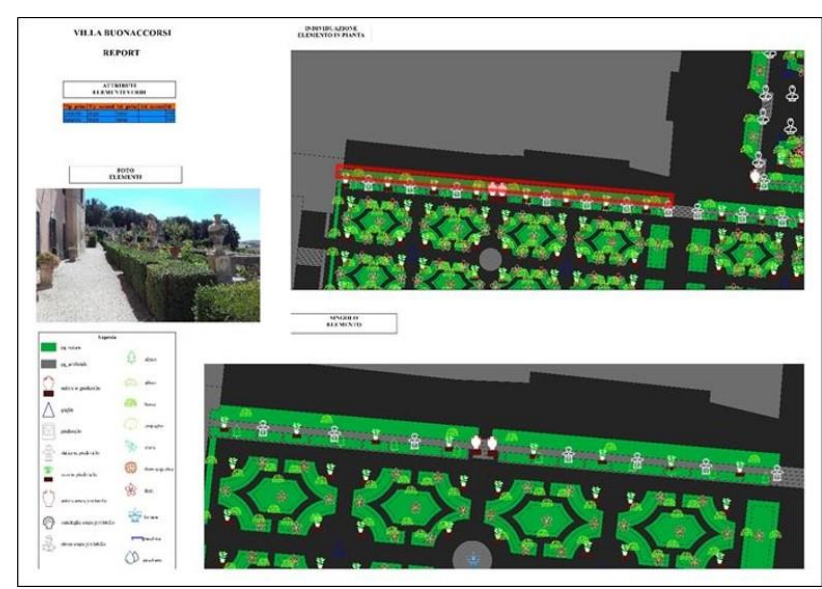

Figure 12. An example of report

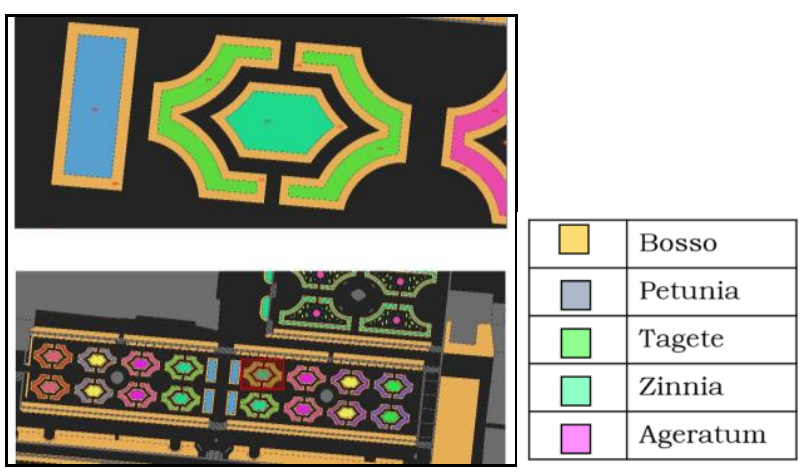

Figure 13. An example of thematic map

\section{CONCLUSION}

The use of GIS platform for the Italian Garden of Villa Buonaccorsi provides an important contribution to systematic diffusion of historical site of data. Through the assignment of layers related to several typological sections, it is possible to create easily thematic maps. The potential of this GIS model can be in the opportunity of integration and updating the database with new data, collected on the end user request. Furthermore, the user can to employ the reports, an easy way to have a different point of view of the Garden. Depending to the final user, different applications can be performed:

- the gardener may query the natural geodatabase of seasonal flowers and require their location;

- the art historian, who wants to know the statues, may query the artificial geodatabase according his own needs;

- the public administration, in this case the municipality of Potenza Picena, could encourage the tourism, plugging routes to discover the history of the town, including the Villa and its surrounding.

\section{REFERENCES}

Boriani M., Cazzani A., Giambruno M. The Naviglio of Martesana: a GIS to manage a protected area. CIPA 2005 XX International Symposium, 26 September - 01 October, 2005, Torino, Italy.

Coccoli C., Treccani G. P., Cavagnini G. G.I.S. e conservazione programmata: un caso applicativo. Il piano di manutenzione della Parrocchiale di Vilminore di Scalve (BG), 2003, MONDOGIS.
Codd E.F. A Relational Model of Data for Large Shared Data Banks, P. Baxendale, Editor, Volume 13, Number 6, June, 1970.

Furukawa Y., Hernández C. Multi-view stereo: A tutorial. Foundations and Trends ${ }^{\circledR}$ in Computer Graphics and Vision, 2015, 9(1-2), 1-148.

Guarnieri A., Masiero A., Piragnolo M., Pirotti F., Vettore A. A geodatabase for multisource data applied to cultural heritage: the case study of Villa Revedin Bolasco, Legnaro (PD). The International Archives of the Photogrammetry, Remote Sensing and Spatial Information Sciences, Volume XLI-B5, 2016 XXIII ISPRS Congress, 12-19 July 2016, Prague, Czech Republic.

Guzzetti F., Fott. P., Viskanic, Cattaneo N., Di Maria F., Privitera A. Specifiche tecniche per la realizzazione del database topografico del patrimonio verde, Milano, 2010, versione 1 .

Historic gardens (Florence Charter 1981), International Council on Monuments and Sites. ICOMOS, December 1982.

Mustaka D. Villa Giardino Buonaccorsi. Il più bell'esempio di giardino all'Italiana delle Marche, Ancona, 2016.

Panzini F., Giardini delle Marche, Milano, Federico Motta Editore S.p.A., 1998.

QGIS Development Team (2016). Version 2.14.18 Essen QGIS Geographic Information System. Open Source Geospatial Foundation Project. http://qgis.osgeo.org

Wüst T., Nebiker S., Landolt R. Applying the 3D GIS DILAS to archaeology and cultural Heritage projects - requirements and first results. The International Archives of the Photogrammetry, Remote Sensing and Spatial Information Sciences, Vol. 34, Part XXX, 2004. 